Tema: Metalurgia Secundária

\title{
AVALIAÇÃO DO TEMPO DE MISTURA EM PANELAS AGITADAS POR GÁS UTIILIZANDO DOIS PLUGS POROSOS*
}

\author{
Bernardo de Oliveira Costa ${ }^{1}$ \\ Caio Nogueira Araújo Diniz ${ }^{1}$ \\ João Paulo Campelo ${ }^{1}$ \\ Pedro Henrique Marques Spínola de Andrade ${ }^{1}$ \\ Roberto Parreiras Tavares ${ }^{2}$
}

\section{Resumo}

O tempo de mistura em panelas de aciaria foi avaliado em diversos trabalhos através de modelamento físico e matemático. A maioria destes trabalhos está focada em analisar os efeitos da vazão de gás e localização dos plugs porosos usados para injeção. Em artigos recentes, o uso de dois plugs de injeção foi investigado, mas ainda há uma controvérsia significativa sobre a melhor posição para injeção de gás. Nestes artigos, a vazão de gás é distribuída igualmente entre os dois plugs de injeção. Neste trabalho, foi feito modelamento físico para avaliar os tempos de mistura de panelas de aciaria equipadas com dois plugs porosos. O modelo físico foi construído na escala de 1:5 de uma panela de 170 toneladas usada em uma planta brasileira. Os tempos de mistura foram apurados usando a injeção de um traçador. Diferentes combinações de posição dos plugs porosos e distribuição da vazão de gás foram ensaiadas. Experimentos de visualização do escoamento também foram desenvolvidos utilizando tufts e injeção de corante. Estes experimentos foram úteis para análise dos resultados.

Palavras-chave: Modelamento físico; Panela de aciaria; Tempo de mistura; Injeção de gás.

\section{EVALUATION OF MIXING TIMES IN GAS AGITATED LADLES USING TWO POROUS PLUGS}

\begin{abstract}
Mixing times in steelmaking ladles have been evaluated in several works using mathematical and physical modeling. Most of these works are focused on analyzing the effects of gas flow rate and location of the porous plug used in gas injection. In recent papers, the use of two porous plugs has been investigated, but there is significant controversy on the best locations for gas injection. In these papers, the gas flow rate is distributed equally between the two porous plugs. In the present paper, physical modeling was used to investigate mixing times in steelmaking ladles equipped with two porous plugs. The physical model was built in a 1:5 scale of a 170 tonnes steelmaking ladle used in a Brazilian plant. The mixing times were evaluated using tracer injection. Different locations for the porous plugs and gas flow rates combinations were investigated. Flow visualization experiments were also carried out using tufts and dye injection. These experiments were useful in analyzing the results.
\end{abstract}

Keywords: Physical modelling; Steelmaking ladle; Mixing time, Gas injection.

1 Graduando em Engenharia Metalúrgica, UFMG, Belo Horizonte, Minas Gerais, Brasil.

2 Engenheiro Metalurgista, PhD, Professor Associado, Departamento de Engenharia Metalúrgica e de Materiais, EEUFMG, Sócio da ABM, Belo Horizonte, Minas Gerais, Brasil.

\footnotetext{
* Contribuição técnica ao 450 Seminário de Aciaria - Internacional, 25 a 28 de maio de 2014,
} 


\section{INTRODUÇÃO}

A demanda e desenvolvimento de novas qualidades de aços passa inevitavelmente por etapas de preparo e ajuste fino que definem o refino secundário. É preciso ser feito controle, em especial, da composição e da temperatura do aço, buscando eliminar gradientes destes dois parâmetros. Alguns processos como desoxidação, desfosforação, dessulfuração, flotação de inclusões, adição de elementos de liga e controle de temperatura são feitos na panela de aciaria e, nesta etapa do refino, a injeção de gás pelo fundo é de fundamental importância para intensificação dos fenômenos de mistura [1].

Há diversas publicações acerca de simulações físicas e matemáticas do processo de mistura por injeção de gás com apenas um plug em panelas [2-4], porém, tratando-se da injeção de gás com configurações que envolvam dois plugs, ainda não existe definição sobre qual a melhor combinação de vazão e posição dos injetores de gás.

A margem para estudos e relevância de experimentos envolvendo mistura pela injeção de gás em dois pontos é ilustrada pela recente publicação de Conejo et al. [5], em que foi usado modelamento físico para estudo dos efeitos da posição, vazão, número de injetores e presença de uma fase sobrenadante sobre o tempo de mistura. O modelo físico construído neste último trabalho citado seguiu a escala de 1:18 de um reator industrial, tendo dimensões significativamente reduzidas. Isto despertou questionamentos sobre a manifestação do regime turbulento de escoamento e seu reflexo sobre o tempo de mistura. A relação das dimensões do modelo e a consequente fração do volume ocupada pela coluna de bolhas é de grande importância nos fenômenos de mistura [4] e a reprodutibilidade das tendências verificadas em diferentes escalas geométricas possui interesse prático principalmente se a utilização dos resultados em cenários industriais é um objetivo.

Em vista da interface com o trabalho de Conejo et al. [5] sobre a utilização de dois injetores de gás, buscou-se uma abordagem complementar, mas ainda mantendo uma margem de similaridade para verificar se haveria algum efeito da escala do modelo sobre o padrão de resultados que evidenciasse discordância. A proposta do presente trabalho é avaliar se ao tomar um determinado valor de vazão injetado por um único plug e distribuí-lo em dois plugs, de forma que a soma das vazões seja igual ao valor de referência, alcança-se taxas de mistura mais elevadas. Para tanto, foram feitas medidas do tempo de mistura para diferentes combinações de vazões dispostas em dois plugs porosos sobre uma matriz de posições relativas entre si.

\section{OBJETIVOS}

Analisar o efeito da localização e distribuição de vazões sobre o tempo de mistura em uma panela de aciaria, considerando a injeção de gás através de dois plugs porosos. Comparar este tempo com aqueles com injeção através de apenas um plug.

\section{METODOLOGIA}

Os experimentos foram conduzidos no Laboratório de Simulação de Processos (LaSiP), parte do Departamento de Engenharia Metalúrgica e de Materiais da Universidade Federal de Minas Gerais.

* Contribuição técnica ao $45^{\circ}$ Seminário de Aciaria - Internacional, 25 a 28 de maio de 2014, Porto Alegre, RS, Brasil. 


\subsection{Descrição do Aparato Experimental}

O modelo físico utilizado é uma panela não cilíndrica feita em acrílico cuja geometria está ilustrada na Figura 1, e que foi feita segundo a escala de 1:5 de uma panela de uma aciaria brasileira. Todas as dimensões da Figura 1 foram cotadas em centímetros. Na vista superior da figura há uma série de posições demarcadas por círculos; uma delas foi chamada Injetor 2 e encontra-se a um distância de $8,25 \mathrm{~cm}$ $(0,25 \mathrm{R})$ do centro do modelo. Ela indica o ponto fixo em que um dos plugs porosos foi mantido em todos os experimentos. Há outros círculos demarcados na Figura 1 de forma diametralmente oposta ao Injetor 2 e em um diâmetro perpendicular. Esses representam as posições onde foi colocado um segundo plug poroso, que, por sua vez, foi chamado Injetor 1 . As variações de posição do Injetor 1 se deram sobre as seguintes distâncias em relação ao centro do modelo: $8,25 \mathrm{~cm}(R / 4) ; 16,5 \mathrm{~cm}(R / 2)$ e $24,75 \mathrm{~cm}(3 \mathrm{R} / 4)$. O ponto de injeção do traçador dista $16,5 \mathrm{~cm}$ do centro do modelo. Rrepresenta a dimensão do raio inferior da panela $(33 \mathrm{~cm})$.

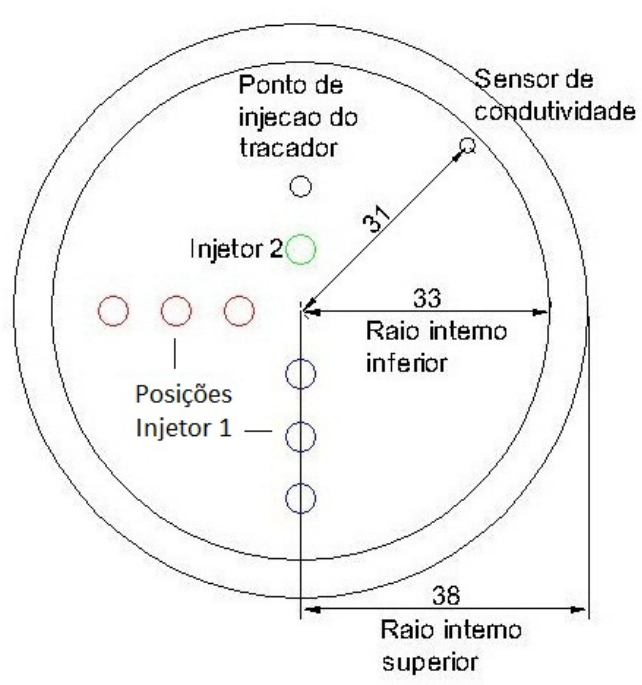

Vista superior

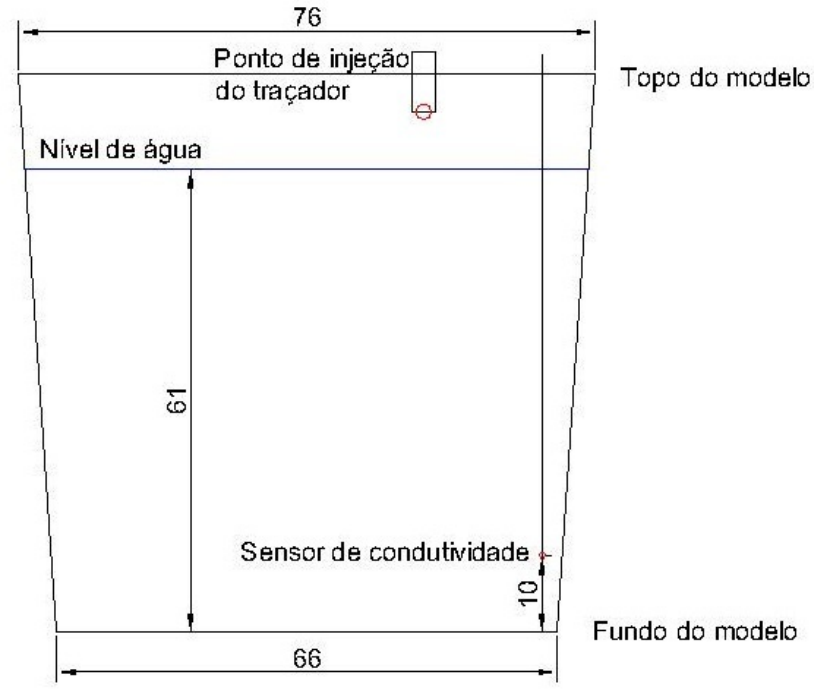

Vista frontal

Figura 1. Vistas superior e frontal do modelo físico. As dimensões encontram-se em centímetros.

O fluido utilizado para simular o aço líquido foi água, escolha essa feita em função da proximidade entre os valores de viscosidade cinemática das duas substâncias. O fluido usado para simular o argônio injetado pelo fundo foi o ar.

\subsection{Determinação dos Tempos de Mistura}

\subsubsection{Determinação da posição do sensor de condutividade}

Com a injeçãode um traçador salino, o banho agitado tem sua condutividade elétrica alterada pontualmente e esta propriedade flutua refletindo a concentração local de $\mathrm{KCl}$. A homogeneização da concentração de $\mathrm{KCl}$ ocorre gradativamente e, quando alcançada, a condutividade elétrica se estabiliza. Logo, a medição da condutividade do banho é capaz de refletir continuamente o desenvolvimento do processo de mistura ao longo do tempo, e permitindo determinar o instante em que a concentração se torna estável. Para medir a condutividade, foi utilizado um condutivímetro da marca HOMIS, modelo 491, e seu sensor foi posicionado segundo a indicação da Figura 1.

* Contribuição técnica ao $45^{\circ}$ Seminário de Aciaria - Internacional, 25 a 28 de maio de 2014, 
A posição desse sensor é de grande importância, pois, enquanto a medida feita por ele é pontual, o objetivo do trabalho passa pela caracterização do processo de mistura ao longo de todo o volume do modelo. Foi preciso então levar em consideração a possibilidade de que em certas regiões a concentração do traçador alcance seu valor final antes que em outras. As regiões onde a mistura demanda mais tempo, devido às pequenas taxas de recirculação, são chamadas zonas mortas e, ao apurar o tempo de mistura nessas regiões, é perfeitamente plausível assumir que o restante do banho se encontra homogeneizado.

Para determinar onde se encontram as zonas mortas foram feitos ensaios de colorimetria, que permitiram inspeção visual direta do regime de escoamento imprimido pela injeção de gás. A técnica utilizada consistiu em tornar o $\mathrm{pH}$ do banho agitado básico através da adição de $50 \mathrm{~mL}$ de uma solução de $\mathrm{NaOH}(0,75 \mathrm{~mol} / \mathrm{L})$, aguardar 3 minutos para garantir que a concentração da base se estabilizasse em todo o banho, e, em seguida, adicionar $5 \mathrm{~mL}$ de uma solução de fenolftaleína $(2 \% \mathrm{~m} / \mathrm{v})$. Imediatamente, seguindo a dispersão da fenolftaleína, o banho assumia nítida coloração rósea, distinguindo o tempo demandado para mistura em cada região do banho. Duas condições foram ensaiadas e filmadas para posterior análise, foram elas: um plug poroso em R/4 com vazão de 30L/min e dois plugs porosos diametralmente opostos, ambos em R/4, com vazões de 15L/min cada. Quatro instantes do teste com dois injetores estão ilustrados na Figura 2.

A partir da análise das filmagens, determinou-se uma região comum às duas configurações de borbulhamento, com 1 e 2 plugs porosos, em que havia fraca recirculação e assim determinou-se a posição fixa do sensor de condutividade.

\subsubsection{Calibração do condutivímetro}

O condutivímetro realiza medidas em $\mu \mathrm{S} / \mathrm{cm}$, unidade de medida de condutividade elétrica, a uma taxa de amostragem de uma medida a cada 2 segundos, e buscouse relacionar os valores indicados pelo aparelho com a concentração do traçador adicionado ao banho, transformando as curvas de variação da condutividade elétrica medida em curvas de variação da concentração local do banho. Para isto foi feita uma calibração do aparelho em escala de bancada. Utilizando um béquer contendo $1,5 \mathrm{~L}$ de água e fazendo gradativas adições ( $5 \mathrm{ml}$ cada) de solução de $\mathrm{KCl} 1 \mathrm{~g} / \mathrm{L}$, mensurou-se a elevação na condutividade elétrica associada a cada incremento na concentração final de $\mathrm{KCl}$ solubilizado. Este processo de calibração foi feito cobrindo a faixa de condutividade na qual os testes foram desenvolvidos, de forma que, quando a condutividade do banho nos experimentos superava o valor máximo incluso na calibração, a água do modelo físico era substituída.

* Contribuição técnica ao $45^{\circ}$ Seminário de Aciaria - Internacional, 25 a 28 de maio de 2014, 

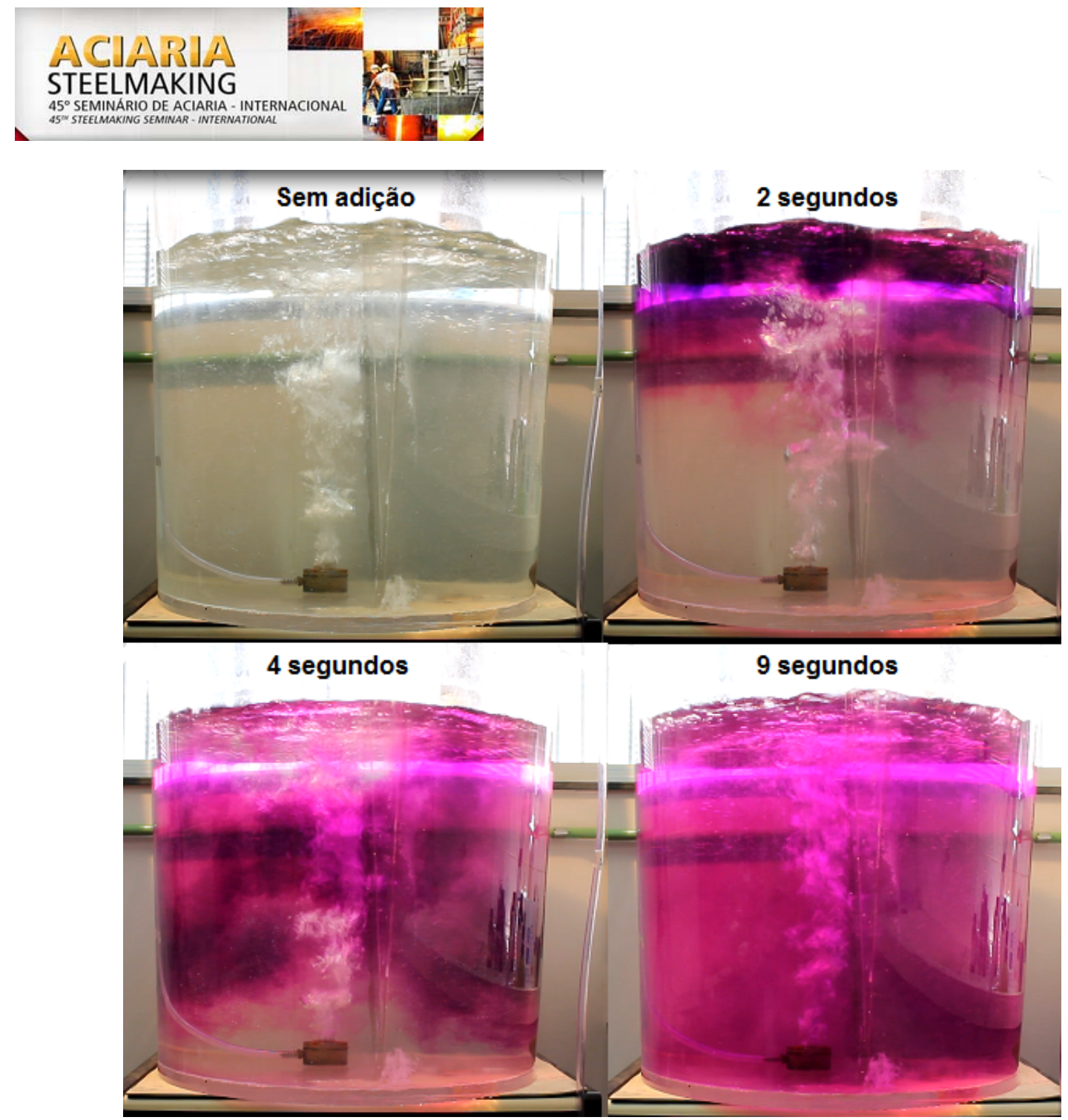

Figura 2. Quadros sucessivos da filmagem do ensaio de colorimetria com 1plug poroso. Tempos marcados após adição de traçador.

Assim, foi possível converter os valores medidos de condutividade em concentração de $\mathrm{KCl}$ no banho, permitindo também a verificação de balanços de massa ao comparar a massa conhecida que foi adicionada e a massa indicada segundo a medida do condutivímetro. Testes cujos balanços de massa indicavam desvios maiores que $5 \%$ entre os valores de referência e amostrados foram descartados.

\subsubsection{Determinação dos tempos de mistura}

Os testes desenvolvidos consistiram em submeter a panela preenchida de água até o nível indicado na Figura 1 a variadas configurações de injeção de gás pelo fundo com os plugs porosos, dispondo diferentes combinações de posição e vazão de gás desses, e realizando adições de uma solução salina que tem a função de traçador.

O traçador usado foi uma solução de $\mathrm{KCl} 20 \mathrm{~g} / \mathrm{L}$ preparada com o sal de grau de pureza analítico previamente seco em uma estufa, pesado em balança analítica e utilizando balão volumétrico de $1 \mathrm{~L}$. A escolha pelo uso do $\mathrm{KCl}$ foi feita em razão da proporcionalidade direta entre $o$ incremento na condutividade elétrica e a concentração desse sal na solução na faixa em que se realizaram os experimentos [6]. Foram feitas adições do traçador sempre no mesmo local na superfície do banho, demonstrado na figura 1 pelo ponto de injeção do traçador.

Nos testes, após a adição do traçador obtinha-se uma curva de variação da concentração do $\mathrm{KCl}$ que sofria bruscas variações e gradativamente se estabilizava em torno de um valor final. Entre cada adição era tomado um tempo de 5 minutos

* Contribuição técnica ao $45^{\circ}$ Seminário de Aciaria - Internacional, 25 a 28 de maio de 2014, Porto Alegre, RS, Brasil. 


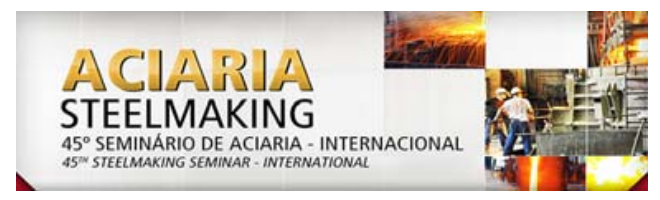

para permitir que a concentração se estabilizasse e houvesse dados suficientes dentro do patamar estável de concentração para se determinar uma média representativa (ao menos 60 valores de concentração) do real valor de concentração do banho homogeneizado. Esse valor médio era tomado anterior e posteriormente à adição do traçador para que fosse avaliada a variação de concentração. Para uniformizar a interpretação das curvas de concentração em função do tempo, foi definida uma concentração adimensional segundo a equação 1:

$$
C^{*} \equiv \frac{C_{(t)}-C_{a n t}}{C_{p o s}-C_{a n t}}
$$

$\mathrm{Na}$ qual $C^{*}$ representa o valor de concentração adimensional, $C_{(t)} \quad 0$ valor de concentração em um determinado instante de tempo, $\mathrm{C}_{\text {ant }}$ a concentração inicial do banho, e $C_{\text {pos }}$ a concentração final do banho. Inicialmente $C^{*}$ oscila em torno do valor $\mathrm{O}\left(\mathrm{C}_{(\mathrm{t})}=\mathrm{C}_{\text {ant }}\right)$, e após a homogeneização se estabiliza em torno do valor 1.

O critério de mistura adotado foi definir o instante de tempo a partir do qual as variações do valor de $C^{*}$ não excedessem a tolerância de $\pm 5 \%$, ou seja, se restringisse à faixa 0,95 a 1,05. Este critério é comumente conhecido como critério de mistura 95\%. A Figura 3 ilustra uma curva de adição do traçador e evidencia o instante definido como tempo de mistura. As duas linhas horizontais demarcam o limite aceitável de variação.

Todo o tratamento dos dados de condutividade obtidos, sua conversão em valores de concentração do traçador, balanços de massa, e montagem das curvas de mistura foram feitos utilizando o Microsoft Excel.

\subsubsection{Combinações de posição e vazão de injeção ensaiadas}

Primeiramente, utilizando apenas o Injetor 2 fixo a uma distância R/4 do centro, avaliou-se a influência da vazão sobre o tempo de mistura. Nesse caso, as vazões ensaiadas variaram de $5 \mathrm{~L} / \mathrm{min}$ a $45 \mathrm{~L} / \mathrm{min}$ seguindo acréscimos de $5 \mathrm{~L} / \mathrm{min}$. Cada valor de vazão teve tempos de mistura medidos em ao menos 10 testes válidos.

Com os dados de tempos de mistura médio de cada vazão e os respectivos desviospadrão, foi feito um teste de hipótese de diferença de médias entre cada par de vazões consecutivas segundo a distribuição $T$, a fim de determinar o valor a partir do qual não se manifesta redução estatisticamente considerável nos tempos de mistura com a elevação da vazão.

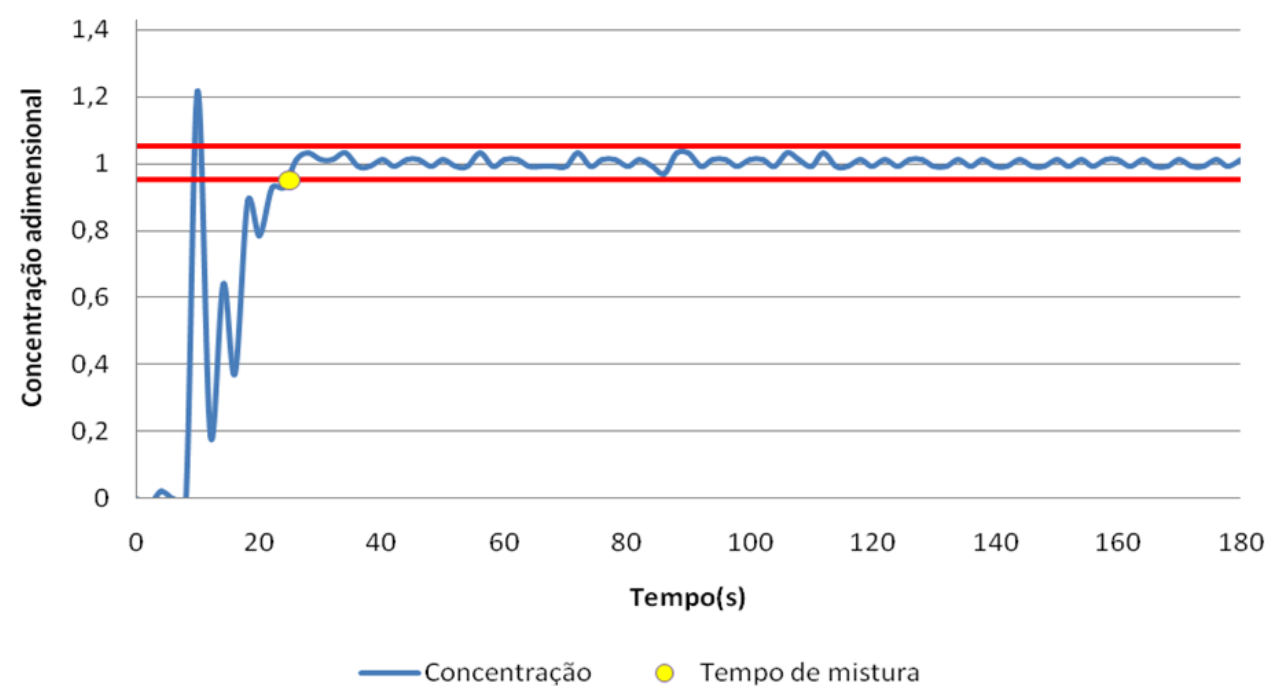

Figura 3. Exemplo de gráfico da curva para determinação do tempo de mistura.

* Contribuição técnica ao $45^{\circ}$ Seminário de Aciaria - Internacional, 25 a 28 de maio de 2014, 


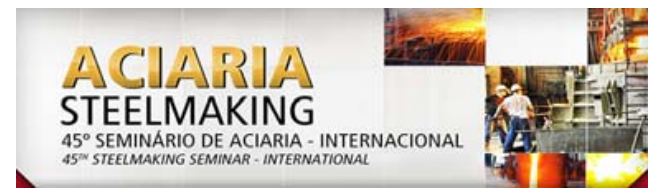

Este valor de vazão então tornou-se referência para montagem do planejamento de ensaios com dois plugs. As configurações analisadas foram definidas sob a condição de que a soma das vazões individuais dos plugs em cada ensaio se igualaria ao valor ótimo determinado previamente. As possíveis combinações de vazões foram então intercaladas com variações na posição de um dos plugs (Injetor 1), enquanto o outro (Injetor 2) permaneceu fixo na posição em que esteve desde os primeiros testes (distante de R/4 do centro). O plug a ser movimentado percorreu as distâncias $8,25 \mathrm{~cm}(R / 4) ; 16,5 \mathrm{~cm}(R / 2)$ e $24,75 \mathrm{~cm}(3 R / 4)$ seguindo, ora o mesmo diâmetro em que se encontra o Injetor 2, e, ora um diâmetro de direção perpendicular ao primeiro (conforme indicado na Figura 1). As combinações de vazão foram feitas também segundo incrementos e deduções de 5L/min em cada um dos plugs. A medida dos valores de vazão foi feita com dois medidores da marca Dwyer modelo GFM-1145.

\section{RESULTADOS E DISCUSSÃO}

\subsection{Injeção de Ar por um Plug Poroso}

A fim de determinar um valor de vazão a partir do qual, estatisticamente, não há mais efeito significativo sobre o tempo de mistura foram feitos experimentos variando a vazão de saída de apenas um plug poroso no banho, que se posicionou em $\mathrm{R} / 4$.Os testes iniciaram com a vazão de $5 \mathrm{~L} / \mathrm{min}$ variando com o acréscimo de $5 \mathrm{~L} / \mathrm{min}$, até o valor máximo de $45 \mathrm{~L} / \mathrm{min}$.

A partir do tratamento matemático sobre os dados de concentração do traçador no tempo, foram tomados os valores médios de tempo de mistura associados a cada vazão de injeção de ar no banho e seus respectivos desvios padrão ao longo de 10 injeções do traçador. A Figura 4 contém a dispersão das médias e barras de desvio padrão nos ensaios com 1 plug poroso.

Todas as vazões possuem um total de 10 testes e foram submetidas a comparações de igualdade de médias segundo um teste de hipótese utilizando médias e variâncias amostrais dos pares de valores de vazões consecutivos [7].

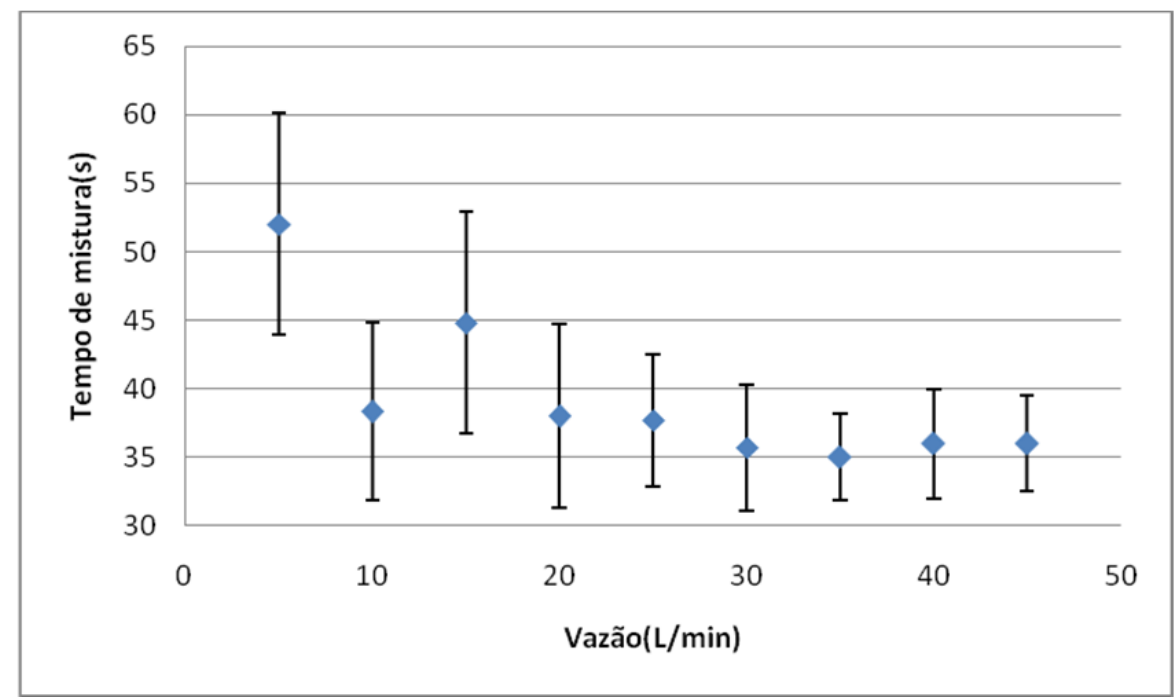

Figura 4. Dados obtidos para relação entre vazão e tempo de mistura.

Comparando os pares consecutivos de médias de tempo de mistura mostrados na Figura 4 concluiu-se que, com um grau de significância igual a 95\%, a partir do valor

* Contribuição técnica ao $45^{\circ}$ Seminário de Aciaria - Internacional, 25 a 28 de maio de 2014, Porto Alegre, RS, Brasil. 
de vazão igual a 20L/min não há alterações no tempo de mistura. Essa, portanto, foi determinada como a vazão ótima para a configuração de injeção com um plug poroso em R/4,sendo ela a utilizada para os testes com dois injetores de ar. Em seguida, buscou-se avaliar o efeito da distribuição desse valor de 20L/min entre dois plugs porosos, e mantendo como base de comparação, para possíveis elevações ou reduções, o tempo de mistura amostrado nesta etapa, que foi igual a 37 segundos.

Uma constatação interessante da configuração de testes com um só plug de inejção de gás é que os maiores desvios nos tempos de mistura estão associados às vazões mais baixas, e que ocorre uma redução à medida que a vazão de gás se eleva. Outro resultado inesperado foi o tempo de mistura associado à vazão de 10L/min. A média se encontra fora do padrão seguido pelas demais vazões. Testes extras com essa vazão foram executados após a conclusão dos demais experimentos a fim de confirmar o valor amostrado. Ao total, foram medidos tempos de mistura ao longo de mais 10 adições do traçador, totalizando uma amostra de 20 tempos de mistura, e que mais uma vez forneceram uma média próxima dos 37 segundos, confirmando a fuga da tendência de redução dos tempos de mistura com o aumento da vazão, mas sendo ainda um tópico que permanece em aberto acerca de suas causas. Simulações matemáticas serão usadas para investigar as causas deste fenômeno.

\subsection{Injeção de Ar por Dois Plugs Porosos}

\subsubsection{Injetores diametralmente opostos}

Os testes com dois injetores de ar foram feitos primeiramente dispondo-os de forma diametralmente oposta, estando o injetor 2 fixado na posição R/4 e o injetor 1 se movimentando ao longo do raio oposto da panela, se posicionando em R/4, R/2 e $3 R / 4$. A vazão foi distribuída entre os dois injetores de tal forma que a vazão total se mantivesse em 20L/min. Para cada disposição foram feitos e registrados pelo menos 10 adições de traçador, a fim de se obter um resultado conclusivo estatisticamente. Os resultados se encontram na Tabela 2. Pode-se notar o aumento do tempo de mistura para a maior parte dos testes, levando à conclusão que a distribuição da vazão de gás não causou redução no tempo de mistura.

Tabela 2. Resultados para injetores diametralmente opostos

\begin{tabular}{|c|c|c|c|c|c|}
\hline & Injetor 1 & Injetor 2 & $\begin{array}{c}\text { Diametralmente } \\
\text { Opostos }\end{array}$ & \\
\hline Posição & R/4 & R/4 & $\begin{array}{c}\text { Tempo de Mistura } \\
\text { (s) T2 }\end{array}$ & Desvio-Padrão & T2-T1 \\
\hline Vazão (L/min) & 5 & 15 & 37,3 & 6,1 & 0,3 \\
\hline Vazão (L/min) & 10 & 10 & 39,4 & 5,5 & 2,4 \\
\hline Vazão (L/min) & 15 & 5 & 43,2 & 6,3 & 6,2 \\
\hline Posição & $\mathbf{R} / 2$ & $\mathbf{R} / 4$ & $\begin{array}{c}\text { Tempo de Mistura } \\
\text { (s) T2 }\end{array}$ & Desvio-Padrão & T2-T1 \\
\hline Vazão (L/min) & 5 & 15 & 40,5 & 5,3 & 3,5 \\
\hline Vazão (L/min) & 10 & 10 & 43,3 & 7,4 & 6,3 \\
\hline Vazão (L/min) & 15 & 5 & 41,8 & 4,7 & 4,8 \\
\hline Posição & $3 R / 4$ & $\mathbf{R} / 4$ & $\begin{array}{c}\text { Tempo de Mistura } \\
\text { (s) T2 }\end{array}$ & Desvio-Padrão & T2-T1 \\
\hline Vazão (L/min) & 5 & 15 & 42,2 & 4,9 & 5,2 \\
\hline Vazão (L/min) & 10 & 10 & 40 & 3,9 & 3,0 \\
\hline Vazão (L/min) & 15 & 5 & 43,9 & 7,1 & 6,9 \\
\hline
\end{tabular}

* Contribuição técnica ao 450 Seminário de Aciaria - Internacional, 25 a 28 de maio de 2014, Porto Alegre, RS, Brasil. 
$\mathrm{Na}$ Tabela 2, a referência T2-T1 mostra o tempo de mistura médio para cada disposição indicada subtraído do valor de 37 segundos, sendo que esse é o tempo associado à vazão de 20L/min em apenas um injetor posicionado em R/4.

Uma possível causa desta elevação nos tempos de mistura é uma interferência negativa das circulações criadas pelas duas plumas, concentrando a movimentação mais intensa ao longo do plano onde se encontram os plugs. A noventa graus deste plano, a movimentação seria lenta, provocando uma homogeneização mais demorada.

\subsubsection{Injetores dispostos em diâmetros perpendiculares}

Os testes com os dois injetores de gás colocados em uma disposição de 90 graus entre si foram realizados seguindo basicamente os mesmos padrões dos testes anteriores. $O$ injetor 2 continua fixo na posição de R/4 enquanto o injetor 1 fica a 90 graus variando a distância do centro em R/4, R/2 e 3R/4. A vazão continuou distribuída de forma que a vazão total se mantivesse 20L/min.

Para cada disposição foram feitos e registrados pelo menos 10 adições de traçador a fim de se obter um resultado conclusivo estatisticamente.

Os resultados se encontram na Tabela 3. Pode-se notar uma diminuição do tempo de mistura na maioria das disposições. Algumas configurações chamam atenção para uma diminuição significativa, próxima de 8 segundos, que representa uma redução superior a $20 \%$ no tempo de mistura quando comparado ao tempo com 1 injetor.

Tabela 3. Resultados para injetores perpendiculares

\begin{tabular}{|c|c|c|c|c|c|}
\hline & Injetor 1 & $\begin{array}{c}\text { Injetor } \\
\mathbf{2}\end{array}$ & Ângulo de 90 & & \\
\hline Posição & $\mathbf{R} / \mathbf{4}$ & $\mathbf{R} / \mathbf{4}$ & Tempo de mistura (s) T2 & $\begin{array}{c}\text { Desvio- } \\
\text { Padrão }\end{array}$ & T2-T1 \\
\hline Vazão (L/min) & 5 & 15 & 34,5 & 6,8 & $-2,5$ \\
\hline Vazão (L/min) & 10 & 10 & 40 & 6,8 & 3 \\
\hline Vazão (L/min) & 15 & 5 & 39,3 & 3,7 & 2,3 \\
\hline Posição & $\mathbf{R} / \mathbf{2}$ & $\mathbf{R} / \mathbf{4}$ & Tempo de mistura (s) T2 & $\begin{array}{c}\text { Desvio- } \\
\text { Padrão }\end{array}$ & T2-T1 \\
\hline Vazão (L/min) & 5 & 15 & 32,8 & 5,9 & $-4,2$ \\
\hline Vazão (L/min) & 10 & 10 & 29 & 5,8 & -8 \\
\hline Vazão (L/min) & 15 & 5 & 33,7 & 7,2 & $-3,3$ \\
\hline Posição & $3 R / 4$ & $\mathbf{R} / 4$ & Tempo de mistura (s) T2 & $\begin{array}{c}\text { Desvio- } \\
\text { Padrão }\end{array}$ & T2-T1 \\
\hline Vazão (L/min) & 5 & 15 & 34,7 & 5,6 & $-2,3$ \\
\hline Vazão (L/min) & 10 & 10 & 35,4 & 4,8 & $-1,6$ \\
\hline Vazão (L/min) & 15 & 5 & 29,9 & 2,7 & $-7,1$ \\
\hline
\end{tabular}

$\mathrm{Na}$ Tabela 3, a referência T2-T1 mostra o tempo de mistura médio para cada disposição indicada subtraído do valor de 37 segundos, sendo que esse é o tempo associado à vazão de 20L/min em apenas um injetor posicionado em R/4.

Uma interpretação cabível e verificada durante os experimentos é que, apesar da proximidade ao dispor os dois plugs em um único quadrante do banho, não se cria movimentação em apenas em um único plano. Com os plugs dispostos a $90^{\circ}$, há uma interferência positiva das plumas, criando uma movimentação mais intensa ao longo de todo o interior da panela. O volume das zonas mortas é reduzido, diminuindo também o tempo de mistura.

* Contribuição técnica ao 45 Seminário de Aciaria - Internacional, 25 a 28 de maio de 2014, 
É importante salientar que os tempos de mistura refletem os ganhos na taxa de recirculação e homogeneização do banho, e que majoritariamente a utilização de dois plugs posicionados perpendicularmente otimizou os resultados obtidos, ao passo que os gastos com gás não sofreram acréscimos.

Estes resultados contrastam com os de CONEJO et al. [5], indicando que há margem para mais investigações..

\subsection{Transposição dos Resultados para Escala Industrial}

Considerando o critério de similaridade baseado na igualdade do número de Froude, é possível transpor a vazão utilizada no modelo para a escala industrial seguindo as equações propostas por Mazumdar e Evans [8].

$$
\begin{aligned}
& Q_{\text {mod }}=Q_{\text {ind }} * \gamma^{2,5}(2) \\
& Q_{\text {ind }}\left(\frac{m^{3}}{s}\right)=Q_{\text {ind }}\left(\frac{N m^{3}}{s}\right) * \frac{1873}{273} * \frac{1}{\left(1+\frac{\rho_{a c ̧ o} * g * H_{\text {ind }}}{2 * 101330}\right)}(3) \\
& Q_{\text {mod }}\left(\frac{m^{3}}{s}\right)=Q_{\text {mod }}\left(\frac{N m^{3}}{s}\right) * \frac{298}{273} * \frac{1}{\left(1+\frac{\rho_{\text {água }} * g * H_{\text {mod }}}{2 * 101330}\right)}(4)
\end{aligned}
$$

Nestas equações, $Q_{\text {ind }}$ representa a vazão de gás na panela industrial, $Q_{\text {mod }}$ a vazão de gás no modelo físico, $g$ é a aceleração da gravidade $\left(9,81 \mathrm{~m} / \mathrm{s}^{2}\right), H_{\text {mod }}$ a altura da coluna de água no modelo físico $(0,61 \mathrm{~m}), H_{\text {ind }}$ a altura da coluna de aço na panela industrial $(3,05 \mathrm{~m}), \rho_{a c ̧ o}$ é a densidade do aço $\left(7.000 \mathrm{~kg} / \mathrm{m}^{3}\right)$, $\rho_{\text {água }}$ é a densidade da água $\left(997 \mathrm{~kg} / \mathrm{m}^{3}\right)$, e $\gamma$ é o fator de escala geométrica $(1 / 5)$.

A partir do valor total de vazão de gás utilizado que foi de $20 \mathrm{~L} / \mathrm{min}$ em todos os experimentos, e utilizando as equações citadas, obtém-se que o valor de vazão correspondente à escala industrial - com base no fator de escala em relação a uma panela de aproximadamente 170 toneladas de aço - seria de $0,0059 \mathrm{Nm}^{3} / \mathrm{s}$ ou $21,1 \mathrm{Nm}^{3} / \mathrm{h}$.

\section{CONCLUSÕES}

As conclusões que podem ser tiradas do presente trabalho são:

- Acerca da variação da vazão em um só plug percebe-se que o aumento da vazão causa uma circulação mais rápida do banho, logo, tempos de mistura menores. A partir de umcerto valor de vazão, os ganhos de tempo são insignificantes;

- Em relação às disposições de dois plugs, os tempos de mistura parecem não apresentar nenhum ganho referente a configuração de plugs diametralmente opostos, chegando em muitos casos a tempos maiores;

- Na configuração de plugs perpendiculares com o injetor 1 em 3R/4 e injetor 2 em $\mathrm{R} / 4 \mathrm{com}$ as vazões de $15 \mathrm{~L} / \mathrm{min}$ e $5 \mathrm{~L} / \mathrm{min}$ respectivamente, a redução do tempo foi muito significativa, assim como na configuração com o injetor 1 em R/2 e o injetor 2 em R/4 ambos com a vazão de 10L/min;

- Distribuindo a vazão em dois plugs e em disposições perpendiculares é possível alcançar tempos de misturas menores. Isso representaria na indústria que, preservando osgastoscomo gás injetado para mistura, a adoção de uma configuração de injeção otimizada forneceria melhores graus de homogeneização térmica e química, com possíveis ganhos de produtividade.

* Contribuição técnica ao 45 Seminário de Aciaria - Internacional, 25 a 28 de maio de 2014, 


\section{Agradecimentos}

Os autores agradecem a FAPEMIG pelo apoio financeiro concedido ao projeto processo TEC - APQ-00373-11 - "Modelamento Físico e Matemático Do Escoamento Multifásico em Sistemas Metalúrgicos".

\section{REFERÊNCIAS}

1 Araújo LA. Manual de Siderurgia - Produção, v.1. São Paulo: Editora Arte \& Ciência; 1997. p.470.

2 Turkoglu $\mathrm{H}$, Farouk B. Mixing time and liquid circulation rate in steelmaking ladles with vertical gas injection. ISIJ International. 1991;31(12):1371-80.

3 Mazumdar D, Guthrie RIL. The physical and mathematical modelling of gas stirred ladle systems. ISIJ International. 1995;35(1):1-20.

4 Sicorski RS. Modelagem numérica aplicada aos fenômenos de escoamento e mistura em modelos físicos de panela de aciaria. Lume Repositório Digital - UFRGS. 2006 [acesso em 13 nov. 2013]. Disponível em: http://www.lume.ufrgs.br/handle/10183/7379.

5 Conejo AN, Kitamura NM, Kim SJ. Effects of top layer, nozzle arrangement, and gas flow rate on mixing time in agitated ladles by bottom gas injection. Metallurgical and Materials Transactions B. 2013;44B:914-923.

6 IC Controls. Technical notes - Conductivity theory and measurement. 2005 [acesso em 11 dez. 2013]. Disponível em: http://www.iccontrols.com/files/4-1.pdf.

7 Inferência estatística para duas amostras [acesso em: 25 nov. 2013]. Disponível em: http://www.cin.ufpe.br/ rmcrs/ESAP/arquivos/cap10.pdf.

8 Mazumdar D, Evans JW. Modeling of steelmaking processes. CRC Press; 2009. p.119.

* Contribuição técnica ao 45 Seminário de Aciaria - Internacional, 25 a 28 de maio de 2014, Porto Alegre, RS, Brasil. 